\title{
RA?EGA
}

O ESPACYO GEOGRÁFICO EM ANÁLISE

\section{AVALIAÇÃO DE RISCO AMBIENTAL DA COMERCIALIZAÇÃO DO PESCADO NA REGIÃO PORTUÁRIA DE MANAUS/AMAZONAS}

\section{ENVIRONMENTAL RISK ASSESSMENT OF FISH MARKETING IN PORT REGION MANAUS / AMAZONAS}

\author{
Esther-Léa Azulay Benayon Cunha \\ Centro Universitário do Norte (UNINORTE) \\ Manaus, AM \\ e-mail:xestherlea@yahoo.com.br \\ Aline Maria Meiguins de Lima \\ Universidade Federal do Pará (UFPA) \\ Belém, $P A$ \\ e-mail: alinemeiguins@gmail.com \\ Francisca das Chagas do Amaral Souza \\ Instituto Nacional de Pesquisas da Amazônia (INPA) \\ Manaus, $A M$ \\ e-mail: francisca.souza@inpa.gov.br \\ Rui Guilherme Cavaleiro de Macedo \\ Universidade Federal do Pará (UFPA) \\ Belém, $P A$ \\ e-mail: rmacedo@ufpa.br \\ Maria de Valdívia Costa Gomes \\ Universidade Federal do Pará (UFPA) \\ Belém, $P A$ \\ e-mail:vnorat@ufpa.br
}

Recebido em: 19/02/2014

Aceito em: 31/08/2015

\section{Resumo}

A segurança alimentar é uma preocupação recorrente, pois trata-se da necessidade de ingestão de alimentos que tenham um padrão de qualidade aceitável, sem risco à saúde. Neste trabalho, avaliam-se as condições de risco ambiental, associadas a uma área de livre comércio de pescado situada em uma região portuária localizada na Zona Sul de Manaus-AM, com $150 \mathrm{~m}$ de extensão, entre os igarapés do Educandos e São Raimundo, próxima a importantes locais comerciais; e as condições sanitárias do pescado durante sua comercialização, acondicionamento e descarte. No processo de análise foram consideradas as condições sanitárias do ambiente e do manipulador do alimento. O método utilizado foi a Análise de Falhas, Modos e Efeitos (FMEA). Os resultados demonstram que a aplicação do FMEA para 


\title{
AVALIAÇÃO DE RISCO AMBIENTAL DA COMERCIALIZAÇÃO DO PESCADO NA REGIÃO PORTUÁRIA DE MANAUS/AMAZONAS
}

cálculo do risco proporciona a identificação dos pontos críticos e a indicação das melhorias possíveis. Quanto ao local de análise, este encontra-se em um grau de risco variando de moderado a alto. Os fatores que podem ocasionar vetores prejudiciais à saúde pública, pelo manuseio inadequado do pescado, pela infraestrutura local e higiene dos alimentos foram observados em $64 \%$ dos casos. E a geração de efluentes líquidos, resíduos sólidos e o consumo de água sem controle de qualidade foi associada a $36 \%$ dos casos. Apesar do quadro desfavorável, esta forma de comércio é uma vocação local e por isso deve passar por um processo de revisão do poder público, para busca de uma qualidade ambiental acompanhada da segurança alimentar do pescado comercializado.

Palavras-chave: Qualidade ambiental, segurança alimentar, FMEA.

\begin{abstract}
The food security is a key concern, since there is the need of food intake; with acceptable standard of quality, that does not imply a health risk. This paper assesses the environmental risk in a port area located in the south of Manaus-AM, with $150 \mathrm{~m}$ long, between the streams of Educandos and São Raimundo, near major shopping sites; and the environmental sanitary condition of the fish during its marketing, packaging and disposal. In the analysis process were considered sanitary conditions of the environment and the food handler. The method used was the Failure Analysis, Modes and Effects (FMEA). The results demonstrate that the application of FMEA for calculating risk provides the identification of critical points, the different intensities of occurrence and it is enabled to indicate possible improvements. Regarding the place of analysis, this is in a degree of risk ranging from moderate to high. The factors that may cause harmful vectors of public health associated with improper handling of fish, the local infrastructure and food hygiene occur in $64 \%$ of cases. In addition, the generation of wastewater, solid waste and without quality control was associated with $36 \%$ of cases. Despite the unfavorable context, this kind of trade is a local vocation, and must go through a review process of the government to search for an environmental quality accompanied by the food safety of fish sold.
\end{abstract}

Keywords: Environmental quality, food safety, FMEA.

\section{INTRODUÇÃO}

O processo de identificação, quantificação e avaliação de riscos pode ser aplicado as mais diversas áreas, desde aquelas vinculadas a desastres naturais (SAITO; PELLERIN, 2013) as associadas as consequências das ações antrópicas sobre o meio ou sobre as próprias relações sociais (GAMA et al., 2013). O espaço urbano é um campo vasto para o desenvolvimento de metodologias de quantificação de riscos ambientais por ser propício a uma série de intervenções que demandam da adequação do espaço as necessidades humanas (LIN et al., 2010). 
Exemplos desta demanda está na necessidade de alimentação, deslocamento e moradia; que por diversas vezes são associadas a locais e formas inadequadas, que afetam diretamente o padrão de qualidade de vida da sociedade ou dos sistemas ambientais envolvidos.

A qualidade ambiental (ZANIN et al., 2005; ENGEL-COX et al., 2009; ROSSATO et al., 2010) é um termo vinculado a diversos fatores que indicam o quanto determinado sistema é favorável (ou não) a manutenção de um padrão de sustentabilidade dos meios envolvidos.

Em se tratando da qualidade ambiental associada a saúde humana, o termo é ampliado para as situações que tendem a comprometer as condições de vida dos envolvidos (FIGUEIREDO et al., 2010; OVRETVEIT, 2013). Desta forma, o risco ambiental vincula-se a qualidade de vida, pela caracterização dos fatores de risco que podem comprometer a saúde humana (SILVA et al., 2010). E um das formas mais recorrentes está na ameaça por meio de alimentos que atuam como elementos de vulnerabilidade dada suas condições de aquisição, transporte, manuseio e consumo (SILVA; CEREJEIRA, 2012).

$\mathrm{Na}$ região Amazônica existe um ambiente propício a ampla manipulação alimentar, uma vez que culturalmente, em função das características deste espaço geográfico, as populações envolvidas tem o hábito do consumo dos bens oriundos das áreas florestais e dos rios, neste caso destaca-se o consumo de peixe (BATISTA; PETRERE, 2007) que é normalmente comercializado em áreas livres ou diretamente com os pescadores locais.

Dada a vulnerabilidade deste produto e sua importância regional, buscou-se avaliar as condições de risco ambiental vinculadas ao seu comércio, considerando a forte relação que as comunidades locais no estado do Amazonas tem com sua relação e consumo.

A contaminação do pescado é de certa forma, conhecida e influenciada por fatores ambientais, associados aos sistemas aquícolas, bem como as condições higiênico-sanitárias adotadas ao longo do processamento, armazenamento, transporte e comercialização do produto final (ANVISA, 2002).

A segurança alimentar preza pela qualidade, o que significa que $O$ alimento deve oferecer um conjunto de atributos ou características inerentes que satisfaz 
requisitos necessários para o consumo humano (BARROS, 2003), não importando o local onde o mesmo é comercializado. A feira livre é considerada um dos locais mais tradicionais de comercialização de alimentos a varejo, sendo uma forma de comércio móvel, com circulação dentro das áreas urbanas (GERMANO; GERMANO, 2008). Uma consequência associada a este perfil é a necessidade de adoção de práticas adequadas de manipulação, exposição, acondicionamento e armazenamento dos alimentos.

Dentre os principais fatores que podem ocasionar alterações na qualidade dos alimentos destacam-se: a falta de infraestrutura e espaço adequado nos boxes, a ausência de equipamentos de conservação, bem como, a falta de água encanada, conservação e higienização inadequadas dos alimentos, dos utensílios e dos manipuladores e a presença de vetores e pragas (LUCCA; TORRES, 2002; NASCIMENTO et al., 2007).

Em decorrência do caráter ambulante da feira, as instalações são necessariamente precárias, especialmente do ponto de vista de saneamento básico e da proteção contra a contaminação ambiental. Isso traz consigo sérios problemas relativos à manipulação de alimentos e ao lixo acumulado pela atividade comercial, que demandam por uma avaliação quanto ao seu potencial de risco ambiental, considerando as variáveis relativas à saúde pública (LAURENTI et al., 2012).

O pescado pode ser veiculador de um grande número de microrganismos patogênicos para o homem (ORDÓÑEZ, 2005); envolvendo, desde a captura ainda nos barcos pesqueiros até sua destinação final, passando por fases de processamento e transporte (SCHLUNDT, 2002; REIJ; DEAN, 2004; HAMADA-SATO et al., 2005). No manuseio de peixes recém-capturados os microrganismos presentes na superfície, guelras e vísceras do animal podem contaminar a carne durante a manipulação, destacando o controle para os do gênero Vibrio ( $V$. parahaemolyticus, V. cholerae). O Staphylococcus aureus encontra no pescado um ambiente favorável para sua multiplicação (BASTI et al., 2006).

Outros agentes bacterianos podem, também, contaminar o pescado e causar risco a saúde (Cepas psicrotróficas de Bacillus cereus, Coliforme fecais, E. coli e Aeromonas spp) muitos destes microrganismos estão relacionados com a qualidade da água, principalmente do gelo utilizado na conservação e/ou procedimentos pós- 
captura (SCHLUNDT, 2002; MATTÉ, 2004). Outro aspecto importante a ser observado na comercialização de pescados é a manutenção da temperatura adequada para cada alimento. Pescados quando expostos em temperaturas inadequadas, alteram-se rapidamente, exigindo um controle rigoroso para garantir a qualidade desses produtos (LUNDGREN et al., 2009).

Considerando as vulnerabilidades associadas a comercialização do pescado é necessário o emprego de procedimentos operacionais à avaliação de risco do processo. A técnica da Análise de Falhas, Modos e Efeitos (Failure, Mode and Effect Analysis - FMEA) foi criada com enfoque nos projetos de novos produtos e processos, mas por sua grande utilidade, passou a ser aplicada de diferentes formas e em diferentes tipos de organizações (RAMOS, 2006). No campo da segurança alimentar, o FMEA pode ser: de processo, quando vinculado a produção de alimentos; ou de serviços, quando da disponibilização direta do alimento ao consumidor (SCIPIONE et al., 2002; ZAMBRANO; MARTINS, 2007; SCOTT et al., 2009; TSAROUHAS et al., 2009; OZILGEN, 2012).

Sendo o pescado a principal fonte proteica da região amazônica o objetivo deste trabalho foi avaliar a situação de risco ambiental associada à condição higiênico-sanitária do pescado durante a sua comercialização, acondicionamento e descarte; a fim de identificar os padrões de qualidade que podem acarretar riscos à saúde em toda cadeia produtiva, e suas implicações em relação à contaminação da orla em torno município de Manaus-AM.

\section{MATERIAIS E MÉTODOS}

A pesquisa foi realizada na região portuária de Manaus-AM, em uma região com um total de 150 metros de extensão, sendo considerada a maior e principal feira que comercializa pescado in natura no município. Localizada na Zona Sul de Manaus, entre os igarapés do Educandos e São Raimundo, seu aspecto geográfico representa uma referência de circulação, acesso e comunicação; estando próximo a importantes entrepostos comerciais.

A área foi escolhida em função da quantidade de feirantes cadastrados e no volume de peixe comercializado, junto a Secretaria Municipal de Produção e Abastecimento. Seu funcionamento é diariamente envolvendo com 100 pontos de 
comercialização, que oferecem os mais diversos e variados tipos de peixes, que obviamente competem com outros agentes de intermediação, como supermercados, mercadinhos e frigoríficos.

A coleta de informações deu-se entre os meses de setembro e outubro de 2012, no período matutino. E a determinação da amostragem foi feita a partir do quesito de representatividade de venda de pescado e frequência no local. A partir destes, chegou-se a um valor de 60 amostras (pontos de comercialização).

Os instrumentos necessários para a realização desta pesquisa foram:

a) Diagnóstico socioeconômico e cultural, com questões objetivas fechadas e abertas pertinentes ao perfil dos feirantes (idade, gênero, estado civil, cor da pele, número de pessoas na família, renda familiar total (mensal), situação de moradia, número de pessoas na residência, tipo de moradia, grau de instrução, bairro, tipo de transporte que utiliza para chegar à feira, anos de trabalho, dias de trabalho por semana, horas de trabalho por dia);

b) Check-list ou listagem de verificação (baseado no Decreto Municipal $n^{\circ} 6.456$, de 12 de julho 1999, Resolução RDC no 216, de 15 de setembro de 2004 da ANVISA e a Resolução RDC no 275, de 21 de outubro de 2002 do Ministério da Agricultura) com 31 perguntas sobre as condições sanitárias da feira, envolvendo os aspectos relativos: as instalações (piso, bancadas, estocagem do lixo); os hábitos higiênicos e vestuários dos manipuladores (asseio pessoal, anti-sepsia das mãos, contato com o dinheiro, utilização de uniforme, banheiros químicos); as fontes de água adotadas; a higiene dos alimentos (separação adequada de cada tipo de produto, condições de higiene e armazenamento forma de embalagem); e os utensílios empregados (materiais não contaminantes e em adequado estado de conservação, fácil higienização, armazenamento apropriado).

c) Formulário com 20 perguntas sobre a comercialização dos peixes (tambaqui, pacu, tucunaré e jaraqui), envolvendo: quantidade do total (por espécie) de peixe comercializado semanalmente; quantidade (por espécie) de peixe comercializado semanalmente segundo os pesos; venda diária (total por espécie); sobras da venda do pescado (ao dia); retorno para refrigeração após a exposição; perdas em quantidade de pescado; receita com a venda dos pescados. Estas informações 
foram coletadas de todos os pontos de comercialização amostrados e mensuradas a partir das informações fornecidas.

As respostas obtidas pelo Check-list sobre as condições sanitárias da feira e pelo formulário sobre a comercialização dos peixes foram adotadas para aplicação da Análise de Falhas, Modos e Efeitos (Failure, Mode and Effect Analysis - FMEA) para avaliação do risco ambiental. De acordo com Leal et al. (2006), as falhas encontradas através dos formulários do FMEA são priorizadas a partir da criticidade das causas, utilizando o Grau de Prioridade de Risco que é composto pelo produto dos seguintes fatores: a ocorrência (frequência da falha), a severidade (gravidade do efeito da falha) e a detecção (facilidade para detectar a falha).

A Figura 1 descreve os índices adotados (HELMAN; ANDERY, 1995; ZAMBRANO; MARTINS, 2007; SANT' ANNA; PINTO, 2010) no preenchimento da avaliação de: Severidade, Ocorrência, Detecção, Abrangência do impacto e Risco ambiental; segundo os seguintes passos:

1. Definição dos ambientes a serem considerados (Descrição das saídas): foram descritas as saídas e a sua função durante o processo produtivo (geração de resíduos, efluentes e odores, nas fases de tratamento, armazenamento e exposição do pescado);

2. Identificação dos aspectos e impactos ambientais dos demais ambientes: os impactos ambientais que ocorrem cotidianamente foram classificados como "real", por outro lado, os impactos que possam vir a ocorrer foram classificados como "potencial";

3. Definição das causas dos aspectos/impactos ambientais: identificação das causas potenciais geradoras de aspectos/impactos ambientais (principalmente as formas de poluição e contaminação do ambiente);

4. Caracterização dos controles atuais de detecção das falhas ou causas: com o levantamento das formas de controle principalmente de consumo, sendo analisados quanto às possibilidades de responderem a implantação das ações pretendidas (relativo as ações de gerenciamento já em execução no setor, para o controle do processo de transporte, limpeza, armazenamento e exposição do pescado); 


\section{AVALIAÇÃO DE RISCO AMBIENTAL DA COMERCIALIZAÇÃO DO PESCADO NA REGIÃO PORTUÁRIA DE MANAUS/AMAZONAS}

5. Desenvolvimento dos Planos de Ações (Ação Recomendada): onde são estipuladas ações de prevenção ou correção para sanar ou conter os aspectos e impactos ambientais.

\begin{tabular}{|c|c|c|c|c|c|c|c|c|c|c|}
\hline $\begin{array}{l}\text { Descrição } \\
\text { das saídas }\end{array}$ & $\begin{array}{c}\text { Tipo de } \\
\text { impacto } \\
\text { ambiental }\end{array}$ & $\begin{array}{l}\text { Efeito do } \\
\text { impacto } \\
\text { ambiental }\end{array}$ & $\begin{array}{l}\text { Causa do } \\
\text { impacto } \\
\text { ambiental }\end{array}$ & $\begin{array}{c}\text { Controles } \\
\text { atuais }\end{array}$ & \multicolumn{4}{|c|}{ SODAR* $^{*}$} & \multicolumn{2}{|c|}{$\begin{array}{c}\text { Controles } \\
\text { ambientais }\end{array}$} \\
\hline & & & & & $\mathbf{s}$ & 0 & A & $F$ & & \\
\hline Classificação & & Severidade (s & do impacto & mbiental & & Peso & & & & \\
\hline & Presençad & produtos muitc & lanosos ao $\mathrm{me}$ & ambiente, de & & & & & Ris & \\
\hline Alta & $\begin{array}{l}\text { remealaçaa } \\
\text { inflamabilid }\end{array}$ & de e patogenic & $\begin{array}{l}\text { as caracteristic } \\
\text { ade. }\end{array}$ & . doxiciadu & & 3 & & & Grau & Peso \\
\hline Moderada & $\begin{array}{l}\text { Ocorrência } \\
\text { grau altera }\end{array}$ & $\begin{array}{l}\text { Ue produtos dan } \\
\text { âo com capacid }\end{array}$ & $\begin{array}{l}\text { sos ao meio an } \\
\text { le de remediaç }\end{array}$ & $\begin{array}{l}\text { oiente, mas cor } \\
\text { o imediata. }\end{array}$ & & 2 & & & Alto & $\geq 0,7$ \\
\hline Baixa & $\begin{array}{l}\text { Produtos } \mathrm{cl} \\
\text { prazo, seno }\end{array}$ & $\begin{array}{l}\text { a alteração ger } \\
\text { a seguir absol }\end{array}$ & $\begin{array}{l}\text { la pode ser obs } \\
\text { da pelo meio o }\end{array}$ & $\begin{array}{l}\text { enada apenas } \\
\text { eliminada por }\end{array}$ & $\begin{array}{l}\text { curto } \\
\text { ste. }\end{array}$ & 1 & & & Médio & $\begin{array}{c}<0,7 \\
a\end{array}$ \\
\hline Classificacão & & Orarrêt & ia (O) imp & acto ambient & & & Peso & & & $\geq 0,5$ \\
\hline Alta & Oimnacto & ambiantal rest & diariamento & & & & 3 & & Baixo & $<0,5$ \\
\hline Moderada & & ambiental & & & & & 2 & & & \\
\hline Baixa & O impacto & ambiental ocol & semestralme & te ou anualm & nte. & & 1 & & & \\
\hline Classificação & & & ecção (D) do & impacto amb & ental & & & Peso & & \\
\hline Alta & $\begin{array}{l}\text { Para dete } \\
\text { sofisticadi }\end{array}$ & $\begin{array}{l}\text { tar o impacto a } \\
\text { s. }\end{array}$ & hbiental é nec & ssário a utilize & ão de & ecnologia & & 3 & & \\
\hline Média & O impacto & ambiental é pe & ebido com a & tilização de m & didore & simples. & & 2 & & \\
\hline Baixa & O impacto & ambiental pod & ser percebido & visualmente. & & & & 1 & & \\
\hline Classificação & & & Abrangência & A) do impact & ambi & ntal & & & Peso & \\
\hline Externa & O impacto & ambiental oco & fora dos limi & es da organize & & & & & 3 & \\
\hline Interna & O impacto & ambiental oco & dentro dos li & ites da organ & tação. & & & & 2 & \\
\hline Pontual & O impacto & ambiental oco & no local ond & está sendo r & alizada & a operação & & & 1 & \\
\hline
\end{tabular}

Figura 1: Modelo de análise do FMEA.

Considerando que o Risco é o produto da vulnerabilidade (V) pela probabilidade $(\mathrm{P})$ de ocorrência de um evento (relativa a porcentagem de registros, em decorrência de falhas que traduzem situações de risco ambiental, associada à condição higiênico-sanitária do pescado durante a sua comercialização, acondicionamento e descarte), sendo (V) a soma dos efeitos de Severidade (S), Ocorrência (O), Detecção (D) e Abrangência (A) (GONÇALVES, 2012):

$$
\begin{gathered}
R=P * V \\
V=\frac{\sum_{i=0}^{n}(S+O+D+A)}{n}
\end{gathered}
$$




\section{RESULTADOS E DISCUSSÃO}

\subsection{Aspectos socioeconômicos}

De acordo com dados levantados junto à população estudada foi constatado que $1,7 \%$ dos feirantes são adolescentes; $48,3 \%$ jovens adultos; $41,7 \%$ com meia idade e 8,3\% terceira idade. Em relação ao gênero foi verificado que $30 \%$ dos feirantes entrevistados são mulheres e 70\% são homens. Quanto ao grau de instrução, 5,0\% dos feirantes não apresentavam nenhum ano de estudo; 33,3\% possuíam ensino fundamental incompleto; 21,7\% concluíram o ensino fundamental; $26,7 \%$ concluíram o ensino médio; $1,7 \%$ concluíram o supletivo; 3,3\% possuíam superior concluído e 8,3\% superior incompleto.

O público alvo foram homens e mulheres de idades variadas. Percebeu-se na prática, que o nível sócio-educacional do feirante atual, não é o mesmo de anos atrás. Se no passado eles eram na maioria analfabetos e provinham na zona rural, hoje, em tempo de desemprego, de crise, as feiras são espaços para que os trabalhadores tenham oportunidade de conseguir algum dinheiro e ajudar no sustento da família. Existem pessoas qualificadas que perderam seus empregos convencionais e que, como forma de sobrevivência se integram à feira. Assim, direta ou indiretamente, as pessoas marginalizadas (excluídas pelo sistema), buscam na feira a retomada da fonte de renda e o sustento familiar (ROCHA et al., 2010).

Em relação aos anos trabalhados constatou-se que $20 \%$ dos feirantes tem entre 1 a 3 anos de experiência; 18,3\% tem entre 4 a 6 anos; 18,3\% têm entre 7 a 9 anos; 43,3\% mais de 10 anos. Em se tratando dos dias trabalhados por semana, $27 \%$ dos feirantes trabalham 4 a 5 dias; e $73 \%, 6$ a 7 dias. Verificou-se que as horas de trabalho por dia de um feirante são: 17\%, 6 a 8 horas, $63 \%, 10$ a 12 horas e $20 \%$ ,18 a 24 horas. De acordo com dados, 1,7\% dos entrevistados auferem uma renda familiar menor que $\mathrm{R} \$ 500,00 /$ mês; $23,3 \%$ uma renda familiar entre $R \$ 500,00$ a $R \$$ $1.000,00 ; 45 \%$, uma renda familiar de $R \$ 1.000,00$ a $R \$ 2.000,00$; e $30 \%$ maior que $R \$ 2.000,00$.

A necessidade de se ter uma rentabilidade é um fator de maior preponderância para aqueles que cursam o ensino médio ou superior, para os que são analfabetos 
ou que cursam o ensino fundamental, os maiores resultados foram para a tradição familiar. É por meio dessa relação de busca pela rentabilidade e de contato com o mundo externo, que a feira é onde os feirantes extraem os meios de produção para sobreviver.

Tal demanda aproxima estes grupos das situações de risco ambiental, uma vez que em busca da renda, os demais valores dificilmente são observados. Para Cartier et al., (2009) existe uma probabilidade alta da maior carga dos danos ambientais se aproximar das populações de baixa renda, que frequentemente encontram-se em situação de vulnerabilidade socioambiental e de desigualdade ambiental (ALVES, 2007; HABERMANN; GOUVEIA, 2008).

\subsection{Dinâmica da comercialização do pescado}

Os fornecedores de peixes ao feirante são formados por intermediários ou revendedores (8,3\%) com pescado oriundo de diversas fontes (piscicultura e extrativa) e produtores diretos $(91,7 \%)$ que são principalmente pescadores (pesca extrativa).

Estes contribuem para o fornecimento de 4 principais tipos de pescado: tucunaré (Cichla kelberi), o tambaqui (Colossoma macropomum), o pacu (Piaractus mesopotamicus) e o jaraqui (Semaprochilodus taeniurus), cujos dados da comercialização são resumidos na Tabela 1. Em função do domínio da pesca extrativa, a maior parte destes é oriunda desta fonte.

O consumo de peixe per capita em Manaus é considerado o mais alto do país, próximo a $180 \mathrm{~kg} / \mathrm{ano}$, sendo que taxa média de consumo do brasileiro é de 25 kg/ano (BRASIL, 2012). As informações contidas na Tabela 1 apontam um comércio ativo, com percentuais de venda acima de $50 \%$ para 3 das 4 espécies mais comercializadas, porém com uma grande quantidade de sobras e perdas, que diretamente vão compor uma massa de resíduo orgânico gerado diariamente. 


\section{AVALIAÇÃO DE RISCO AMBIENTAL DA COMERCIALIZAÇÃO DO PESCADO NA REGIÃO PORTUÁRIA DE MANAUS/AMAZONAS}

Tabela 1. Aspectos da comercialização do pescado.

\begin{tabular}{|c|c|c|c|c|c|c|c|c|}
\hline $\begin{array}{c}\text { Variáveis } \\
\text { quantificadas }\end{array}$ & \multicolumn{2}{|c|}{ Tucunaré } & \multicolumn{2}{|c|}{ Tambaqui } & \multicolumn{2}{|c|}{ Pacu } & \multicolumn{2}{|c|}{ Jaraqui } \\
\hline $\begin{array}{l}\text { Quantidade do total } \\
\text { (por espécie) de } \\
\text { peixe } \\
\text { comercializado } \\
\text { semanalmente (\%) }\end{array}$ & \multicolumn{2}{|c|}{55,9} & \multicolumn{2}{|c|}{50} & \multicolumn{2}{|c|}{28,9} & \multicolumn{2}{|c|}{20,9} \\
\hline \multirow{9}{*}{$\begin{array}{l}\text { Quantidade (por } \\
\text { espécie) de peixe } \\
\text { comercializado } \\
\text { semanalmente } \\
\text { segundo os pesos } \\
(\%)\end{array}$} & $100 \mathrm{~kg}$ & 17,6 & $300 \mathrm{~kg}$ & 50 & $20 \mathrm{~kg}$ & 7,9 & $20 \mathrm{~kg}$ & 18,6 \\
\hline & $150 \mathrm{~kg}$ & 2,9 & $375 \mathrm{~kg}$ & 7,1 & $21 \mathrm{~kg}$ & 5,3 & $22 \mathrm{~kg}$ & 4,7 \\
\hline & $200 \mathrm{~kg}$ & 11,8 & $400 \mathrm{~kg}$ & 10,7 & $30 \mathrm{~kg}$ & 28,9 & $30 \mathrm{~kg}$ & 18,6 \\
\hline & $250 \mathrm{~kg}$ & 5,9 & $500 \mathrm{~kg}$ & 7,1 & $40 \mathrm{~kg}$ & 23,7 & $40 \mathrm{~kg}$ & 4,7 \\
\hline & $300 \mathrm{~kg}$ & 55,9 & $800 \mathrm{~kg}$ & 7,1 & $50 \mathrm{~kg}$ & 10,5 & $50 \mathrm{~kg}$ & 4,7 \\
\hline & \multirow{4}{*}{$350 \mathrm{~kg}$} & \multirow{4}{*}{5,9} & \multirow{4}{*}{$1000 \mathrm{~kg}$} & \multirow{4}{*}{17,9} & $60 \mathrm{~kg}$ & 7,9 & $60 \mathrm{~kg}$ & 18,6 \\
\hline & & & & & $200 \mathrm{~kg}$ & 5,3 & $70 \mathrm{~kg}$ & 7,0 \\
\hline & & & & & \multirow{2}{*}{$250 \mathrm{~kg}$} & \multirow{2}{*}{10,5} & $80 \mathrm{~kg}$ & 20,9 \\
\hline & & & & & & & $250 \mathrm{~kg}$ & 2,3 \\
\hline $\begin{array}{l}\text { Venda diária (total } \\
\text { por espécie) }(\%)\end{array}$ & \multicolumn{2}{|c|}{$97,1-100$} & \multicolumn{2}{|c|}{32,1} & \multicolumn{2}{|c|}{52,6} & \multicolumn{2}{|c|}{74,4} \\
\hline $\begin{array}{l}\text { Sobras da venda do } \\
\text { pescado (ao dia) } \\
(\%)\end{array}$ & \multicolumn{2}{|c|}{88,2} & \multicolumn{2}{|c|}{60,7} & \multicolumn{2}{|c|}{52,6} & \multicolumn{2}{|c|}{46,5} \\
\hline $\begin{array}{l}\text { Retorno para } \\
\text { refrigeração após a } \\
\text { exposição (\%) }\end{array}$ & \multicolumn{2}{|c|}{94,1} & \multicolumn{2}{|c|}{92,9} & \multicolumn{2}{|c|}{94,7} & \multicolumn{2}{|c|}{72,1} \\
\hline $\begin{array}{l}\text { Perdas em } \\
\text { quantidade (\%)de } \\
\text { pescado }\end{array}$ & \multicolumn{2}{|c|}{82,4 (12kg/dia) } & \multicolumn{2}{|c|}{$\begin{array}{c}71,4 \\
(7 \mathrm{~kg} / \mathrm{dia})\end{array}$} & \multicolumn{2}{|c|}{$\begin{array}{c}73,7 \\
(3,5 \mathrm{~kg} / \mathrm{dia})\end{array}$} & \multicolumn{2}{|c|}{$\begin{array}{c}43,2 \\
(5,5 \mathrm{~kg} / \mathrm{dia})\end{array}$} \\
\hline $\begin{array}{l}\text { Receita com a } \\
\text { venda dos } \\
\text { pescados (\%) }\end{array}$ & \multicolumn{2}{|c|}{$\begin{array}{c}26,5 \\
(\mathrm{R} \$ 2.100,00)\end{array}$} & \multicolumn{2}{|c|}{$\begin{array}{c}34,5(\mathrm{R} \$ \\
5.619,00)\end{array}$} & \multicolumn{2}{|c|}{$\begin{array}{c}45 \\
(R \$ 3.370,00)\end{array}$} & \multicolumn{2}{|c|}{$\begin{array}{c}27,9 \\
(\mathrm{R} \$ 1.600,00)\end{array}$} \\
\hline
\end{tabular}

Fonte: Org. do Autor.

\subsection{Avaliação segundo as Boas Práticas de Fabricação (BPF)}

Com base na Resolução RDC n 216/04 da Agência Nacional de Vigilância Sanitária (ANVISA) a feira, de acordo com os itens avaliados, apresenta várias não conformidades. Os cinco itens avaliados (instalações, hábitos higiênicos e vestuário dos manipuladores, água, higiene dos alimentos e utensílios) apresentaram irregularidades de funcionamento. Isto permite inferir que a presença de resíduos (lixo) e animais, nas imediações da feira, favorece ao comprometimento dos peixes vendidos na mesma (Figura 2). 


\section{AVALIAÇÃO DE RISCO AMBIENTAL DA COMERCIALIZAÇÃO DO PESCADO NA REGIÃO PORTUÁRIA DE MANAUS/AMAZONAS}

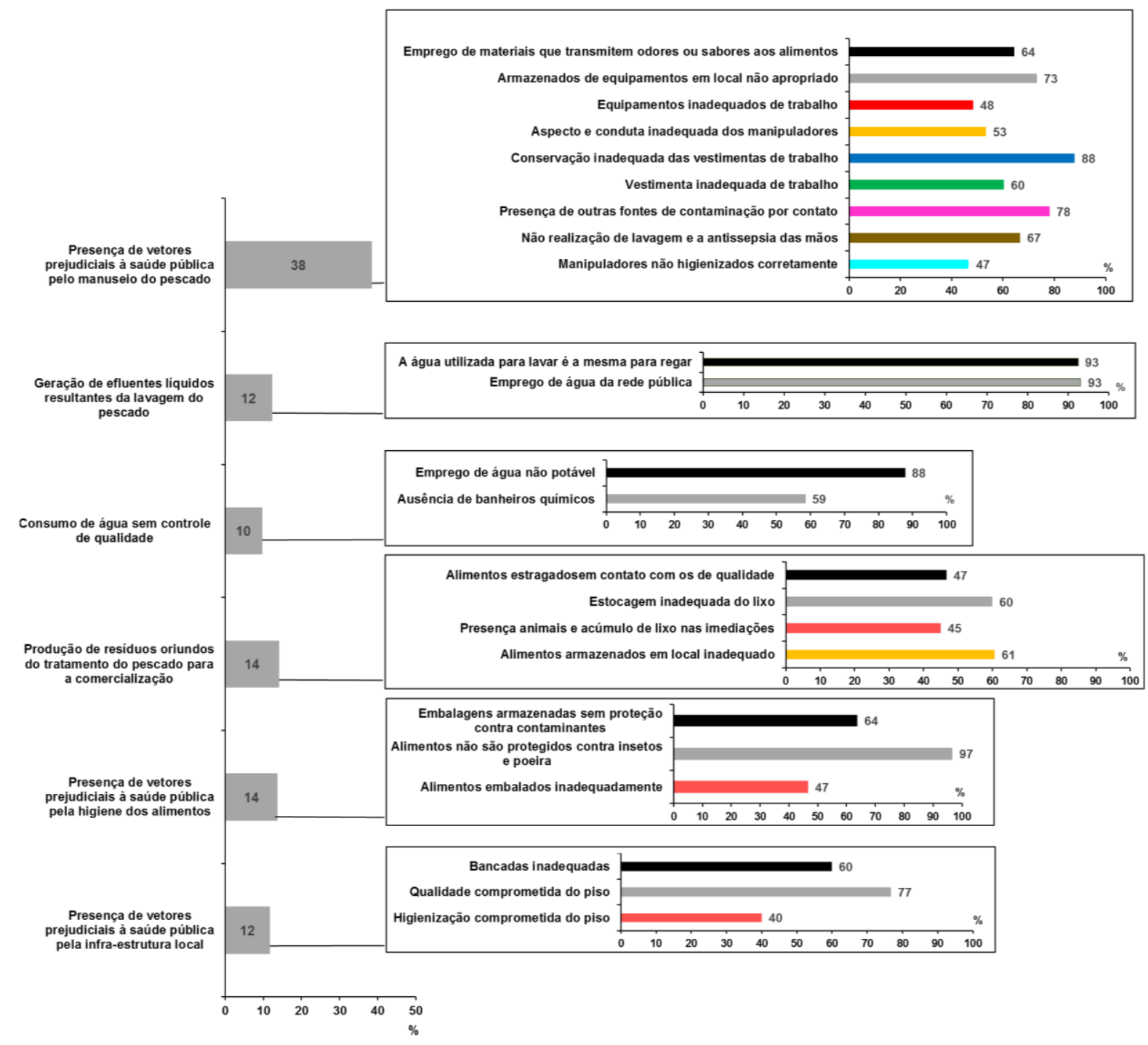

Figura 2: Variáveis consideradas na determinação das probabilidades.

De forma geral em $64 \%$ dos casos identificam-se fatores que podem ocasionar vetores prejudicais a saúde pública, pelo manuseio inadequado do pescado, pela infra-estrutura local e higiene dos alimentos; e em a 36\% é observada a geração de efluentes líquidos, resíduos sólidos e o consumo de água sem controle de qualidade.

De forma mais específica, em $76,7 \%$ dos casos o piso não se encontra em adequado estado de higienização (livre de defeitos, rachaduras, buracos); 60\% das bancadas avaliadas tem problemas de conservação e não possuem uma área adequada para o armazenamento do lixo. As bancadas muitas vezes estão quebradas, rachadas e sujas e ainda possuem contato direto com os peixes. Elas 
não são lavadas diariamente, favorecendo o desenvolvimento de microrganismos durante o manuseio, estocagem e distribuição.

As superfícies dos equipamentos, móveis e utensílios utilizados na manipulação encontram-se com imperfeições que comprometem a higiene dos mesmos, podendo ser fontes de contaminação. Assim como a edificação, as instalações, os equipamentos e móveis. Há grande quantidade de insetos nas superfícies; não existindo controle eficiente, com o objetivo de impedir a atração, o abrigo, o acesso e/ou proliferação dos mesmos. A remoção e limpeza inapropriadas destes lugares podem favorecer a permanência de parasitas, fatores estes associados como de risco à saúde púbica como discutido em Mendes et al. (2011) e Sánchez-Ortiz e Leite (2011).

Os coletores utilizados para deposição dos resíduos das áreas de manipulação não são dotados de tampas acionadas sem contato manual e os resíduos quando coletados são estocados em tambores abertos e depositados na área externa da feira. A gravidade deste comportamento pode ser exemplificada pelo obtido por Silva et al. (2011) que determinaram 466 estirpes bacterianas em resíduos sólidos lixiviados enriquecidos em matéria orgânica.

Quanto ao quesito de hábitos higiênicos e vestuário, verificou-se que os manipuladores não seguem as boas práticas de higienização. Em 46,7\% dos casos o asseio pessoal (boa apresentação, mãos limpas, unhas curtas e sem esmalte, sem adornos (anéis, pulseiras e brincos), manipuladores barbeados, com os cabelos protegidos) é comprometido; 66,7\% não realizam a lavagem e a anti-sepsia das mãos antes de manusear o alimento; 60,3\% não utilizam uniforme de trabalho de cor clara, adequado à atividade e 87,9\% não estão com uniformes limpos e em bom estado de conservação. Foi considerado alto (53,4\%) o índice de manipuladores que espirram, tossem, fumam ou praticam algum ato que possam contaminar os alimentos.

Os banheiros químicos não possuem pias para higienização das mãos e se localizam bem próximos as instalações das feiras, sendo o abastecimento de água realizado pela rede pública. Para Souza (2006) a higiene dos manipuladores de alimentos é um fator que deve ser gerenciado e controlado para não comprometer a segurança dos alimentos e evitarem contaminações e toxinfecções. 


\section{AVALIAÇÃO DE RISCO AMBIENTAL DA COMERCIALIZAÇÃO DO PESCADO NA REGIÃO PORTUÁRIA DE MANAUS/AMAZONAS}

$\mathrm{Na}$ higiene dos alimentos observou-se que os peixes entram em contato uns com os outros propiciando a contaminação cruzada. Estes sofrem a incidência direta de insetos, poeiras, chuvas e raios solares, o que favorece a modificação na composição nutricional, textura e cor dos alimentos. O manejo inadequado pode resultar na sobrevivência e multiplicação de microrganismos psicotróficos; podendo desencadear surtos de Doenças Transmitidas por Alimentos (DTA's), em geral associadas a náuseas, vômitos, febres, cólicas, cefaleias e diarreias (REIJI; DEAN, 2004; HAMADA-SATO et al., 2005).

Os valores de perdas identificados (variando de $12 \mathrm{~kg} / \mathrm{dia}$ a $5,5 \mathrm{~kg} / \mathrm{dia}$ ) podem ser associados também a deficiência de higiene e a falta de cuidado com a preservação. O perfil caracterizado mostra que apesar do baixo nível de escolaridade da maioria, o período de experiência no setor deveria compensar, porém o observado demonstra a falta, ou dificuldade, de associar uma proposta de melhoria das condições de oferta do produto à possibilidade de potencializar a renda e reduzir as perdas.

\subsection{Avaliação de risco segundo a FMEA}

Considerando o perfil socioeconômico e os aspectos de comercialização foram possíveis identificar os principais aspectos que intervêm na gestão ambiental da feira, por meio da avaliação de risco decorrente das condições inadequadas do pescado e consequente geração de resíduos sólidos e efluentes líquidos. A Tabela 2 apresenta a análise dos aspectos ambientais de maior influência.

Tabela 2. Análise dos aspectos ambientais de maior influência, segundo a FMEA.

\begin{tabular}{|c|c|c|c|c|c|}
\hline $\begin{array}{c}\text { Descrição das } \\
\text { saídas }\end{array}$ & $\begin{array}{c}\text { Tipo de impacto } \\
\text { ambiental }\end{array}$ & Efeito & Causa & $\begin{array}{l}\text { Controles } \\
\text { atuais }\end{array}$ & $\begin{array}{c}\text { Controles } \\
\text { ambientais }\end{array}$ \\
\hline $\begin{array}{l}\text { Presença de } \\
\text { vetores } \\
\text { prejudiciais à } \\
\text { saúde pública } \\
\text { pela infraestrutura } \\
\text { local }\end{array}$ & $\begin{array}{l}\text { Afetam a saúde } \\
\text { dos } \\
\text { consumidores e } \\
\text { frequentadores } \\
\text { locais }\end{array}$ & $\begin{array}{l}\text { Geração de } \\
\text { surtos locais }\end{array}$ & $\begin{array}{l}\text { Instalações não } \\
\text { adequadas ao } \\
\text { comércio do } \\
\text { pescado }\end{array}$ & $\begin{array}{l}\text { Lavagem } \\
\text { de } \\
\text { bancadas, } \\
\text { equipament } \\
\text { os e pisos } \\
\text { com água } \\
\text { não potável }\end{array}$ & $\begin{array}{l}\text { Investimento } \\
\text { na } \\
\text { infraestrutura } \\
\text { local }\end{array}$ \\
\hline $\begin{array}{l}\text { Presença de } \\
\text { vetores } \\
\text { prejudiciais à } \\
\text { saúde pública } \\
\text { pelo manuseio do } \\
\text { pescado }\end{array}$ & $\begin{array}{l}\text { Afetam a saúde } \\
\text { dos } \\
\text { consumidores e } \\
\text { frequentadores } \\
\text { locais }\end{array}$ & $\begin{array}{l}\text { Geração de } \\
\text { surtos locais }\end{array}$ & $\begin{array}{l}\text { Emprego de } \\
\text { utensílios e } \\
\text { vestimentas } \\
\text { inadequados para } \\
\text { o tratamento do } \\
\text { pescado }\end{array}$ & $\begin{array}{l}\text { Iniciativas } \\
\text { pontuais de } \\
\text { adequação }\end{array}$ & $\begin{array}{l}\text { Treinamento } \\
\text { e implantação } \\
\text { de rotinas } \\
\text { adequadas } \\
\text { de limpeza } \\
\text { local }\end{array}$ \\
\hline
\end{tabular}




\section{AVALIAÇÃO DE RISCO AMBIENTAL DA COMERCIALIZAÇÃO DO PESCADO NA REGIÃO PORTUÁRIA DE MANAUS/AMAZONAS}

(Continuação)

\begin{tabular}{|c|c|c|c|c|c|}
\hline $\begin{array}{l}\text { Presença de } \\
\text { vetores } \\
\text { prejudiciais à } \\
\text { saúde pública } \\
\text { pela higiene dos } \\
\text { alimentos }\end{array}$ & $\begin{array}{l}\text { Afetam a saúde } \\
\text { dos } \\
\text { consumidores e } \\
\text { frequentadores } \\
\text { locais }\end{array}$ & $\begin{array}{l}\text { Geração de } \\
\text { surtos locais }\end{array}$ & $\begin{array}{l}\text { Condutas e } \\
\text { rotinas que } \\
\text { ameaçam a } \\
\text { qualidade do } \\
\text { produto ofertado }\end{array}$ & $\begin{array}{l}\text { Iniciativas } \\
\text { pontuais de } \\
\text { adequação }\end{array}$ & $\begin{array}{l}\text { Fiscalização } \\
\text { e adequação } \\
\text { as normas } \\
\text { vigentes com } \\
\text { aplicação de } \\
\text { penalidade e } \\
\text { multa }\end{array}$ \\
\hline $\begin{array}{l}\text { Geração de } \\
\text { resíduos oriundos } \\
\text { do tratamento do } \\
\text { pescado para a } \\
\text { comercialização }\end{array}$ & $\begin{array}{l}\text { Produção de } \\
\text { resíduos } \\
\text { orgânicos }\end{array}$ & $\begin{array}{l}\text { Intensificaçã } \\
\text { o da ação de } \\
\text { micro- } \\
\text { organismos }\end{array}$ & $\begin{array}{l}\text { Ausência ou } \\
\text { insuficiência no } \\
\text { controle da } \\
\text { produção dos } \\
\text { resíduos }\end{array}$ & $\begin{array}{l}\text { Recipientes } \\
\text { de depósito } \\
\text { e limpeza } \\
\text { sazonal }\end{array}$ & $\begin{array}{l}\text { Definição de } \\
\text { um padrão de } \\
\text { armazename } \\
\text { nto destes } \\
\text { resíduos até } \\
\text { sua completa } \\
\text { remoção }\end{array}$ \\
\hline $\begin{array}{l}\text { Consumo de } \\
\text { água sem } \\
\text { controle de } \\
\text { qualidade }\end{array}$ & $\begin{array}{l}\text { Consumo de } \\
\text { água não tratada }\end{array}$ & $\begin{array}{l}\text { Contaminaç } \\
\text { ão da água e } \\
\text { do solo }\end{array}$ & $\begin{array}{l}\text { A água } \\
\text { contaminada para } \\
\text { limpeza e } \\
\text { tratamento dos } \\
\text { peixes novos }\end{array}$ & $\begin{array}{l}\text { Água } \\
\text { transportad } \\
\text { a e utilizada } \\
\text { de forma } \\
\text { incorreta } \\
\end{array}$ & $\begin{array}{l}\text { Água tratada } \\
\text { direto nos } \\
\text { boxes dos } \\
\text { feirantes }\end{array}$ \\
\hline $\begin{array}{l}\text { Geração de } \\
\text { efluente líquido } \\
\text { resultante da } \\
\text { lavagem do } \\
\text { pescado }\end{array}$ & $\begin{array}{l}\text { Produção de } \\
\text { esgoto }\end{array}$ & $\begin{array}{l}\text { Poluição da } \\
\text { água e do } \\
\text { solo }\end{array}$ & $\begin{array}{l}\text { Poluição } \\
\text { Ambiental }\end{array}$ & $\begin{array}{l}\text { Esgoto sem } \\
\text { ralo } \\
\text { sifonado }\end{array}$ & $\begin{array}{l}\text { Implantação } \\
\text { de sistema de } \\
\text { saneamento } \\
\text { adequado }\end{array}$ \\
\hline
\end{tabular}

Fonte: Org. do Autor.

A Figura 2 resume as variáveis consideradas para definição da probabilidade de ocorrência a partir dos levantamentos efetuados e a Tabela 3 a análise de risco efetuada a partir destes.

Tabela 3. Análise de risco ambiental: Probabilidade - P; Severidade - S; Ocorrência - O; Detecção D; Abrangência do impacto - A; V - Vulnerabilidade; R - Risco.

\begin{tabular}{|c|c|c|c|c|c|c|c|}
\hline Variáveis & $\mathbf{P}$ & S & 0 & D & A & V & $\mathbf{R}$ \\
\hline $\begin{array}{l}\text { Geração de vetores prejudiciais à saúde pública pela } \\
\text { infraestrutura local }\end{array}$ & 0,6 & 3,0 & 3,0 & 2,0 & 2,0 & 0,8 & 0,5 \\
\hline $\begin{array}{l}\text { Geração de vetores prejudiciais à saúde pública pelo } \\
\text { manuseio do pescado }\end{array}$ & 0,6 & 3,0 & 3,0 & 2,0 & 1,0 & 0,8 & 0,5 \\
\hline $\begin{array}{l}\text { Geração de vetores prejudiciais à saúde pública pela higiene } \\
\text { dos alimentos }\end{array}$ & 0,7 & 3,0 & 3,0 & 3,0 & 3,0 & 1,0 & 0,7 \\
\hline $\begin{array}{l}\text { Geração de resíduos oriundos do tratamento do pescado } \\
\text { para a comercialização }\end{array}$ & 0,5 & 3,0 & 3,0 & 2,0 & 3,0 & 0,9 & 0,5 \\
\hline Consumo de água sem controle de qualidade & 0,7 & 3,0 & 3,0 & 2,0 & 2,0 & 0,8 & 0,6 \\
\hline $\begin{array}{l}\text { Geração de efluente líquido re } \\
\text { pescado }\end{array}$ & 0,9 & 3,0 & 3,0 & 2,0 & 3,0 & 0,9 & 0,9 \\
\hline
\end{tabular}

Fonte: Org. do Autor.

De acordo com os dados apresentados o risco ambiental varia de moderado a alto para seus frequentadores por funcionar com más condições sanitárias, falta de higiene, de estruturação dos boxes, desorganização, pouco espaço livre para 
circulação dos consumidores, presenças de animais e insetos. O grau de risco identificado demonstra que o ambiente é comprometido pelas condições sanitárias identificadas, sendo este classificado como poluído, devido às alterações nas suas características visuais e olfativas.

Por meio do FMEA pode-se identificar o que llizaliturri et al. (2009) chamam de avaliação integrada de riscos, pois a identificação da "Falhas" como indicadoras das condições de "Perigo" possibilita uma visão sistêmica da área analisada e assim definir medidas de controle adequadas.

Como a análise foi vinculada diretamente ao potencial da população ao consumo de alimentos expostos à condições inadequadas de manuseio e armazenamento, sempre o risco tenderá a ser alto, pois o fator de saúde do indivíduo definirá se ele tem ou não maior vulnerabilidade a ingestão destes produtos (GOMES, 2007; AZEVEDO, 2008).

Dentre as medidas imediatas destaca-se a instalação de contêineres para acondicionamento dos resíduos durante o período de funcionamento da feira, para que o ambiente se torne mais limpo, facilitando ainda o trabalho de limpeza da via. Ações de educação ambiental podem contribuir, na qualificação das pessoas envolvidas no processo tais como administrador, fiscais, feirantes e etc.; para um melhor manuseio dos alimentos, amenizando a poluição decorrente do acúmulo de resíduos.

A mitigação ou o gerenciamento do risco a saúde instalado dado as condições de controle alimentar, demandam também por uma discussão sobre a dimensão social do risco, a complexidade e a multiplicidade de causas das questões de saúde, em áreas urbanas (ALVES, 2007). Em geral a remediação desta situação deverá vir acompanhada de estratégias inovadoras para identificar e reduzir a exposição ao risco, sendo integradora e intersetorial em saúde e ambiente (CARTIER et al, 2009). $O$ enfoque integrador propicia que sejam envolvidas as dimensões sociais e culturais do risco (ARAÚJO; GÜNTHER, 2009). 


\section{CONCLUSÕES}

Os resultados obtidos indicam que existe um real potencial de comprometimento do pescado comercializado, pois as condições locais não estão de acordo com a legislação municipal e federal, com graves problemas higiênicosanitários que podem comprometer a qualidade dos produtos e colocar em risco a saúde do consumidor.

É fundamental o trabalho intenso de conscientização dos feirantes e principalmente dos consumidores sobre práticas de higiene e sua importância na saúde pública. Além da fiscalização da forma de comercialização do pescado. Destaca-se a necessidade de estudos complementares como avaliação microbiológica e físico-química, com objetivo de determinar a qualidade do pescado.

A FMEA como método de análise pode ser aplicado de forma rotineira pelo poder público, fazendo parte de um processo de monitoramento e fiscalização continuados, de tal forma que ao longo do período, possam ser registradas as melhorias de processo e o surgimento de novas falhas, principalmente referentes à qualidade do pescado comercializado, com a amostragem e análise continuada destes, evitando assim a possibilidade de ocorrência de eventos com graves consequências aos consumidores do produto local.

\section{REFERÊNCIAS}

ALVES, H. P. F. Desigualdade ambiental no município de São Paulo: análise da exposição diferenciada de grupos sociais a situações de risco ambiental através do uso de metodologias de geoprocessamento. Revista Brasileira de Estudos Populacionais, v. 24, n. 2, p. 301-316, 2007.

ANVISA. Agência Nacional de Vigilância Sanitária. Resolução RDC no 275, de 21 de outubro de 2002. Dispõe sobre o Regulamento Técnico de Procedimentos Operacionais Padronizados e aplicados aos Estabelecimentos Produtores/Industrializadores de Alimentos e a Lista de Verificação das Boas Práticas de Fabricação em Estabelecimentos Produtores/Industrializadores de Alimentos. D.O.U. de 06/11/2002. 
ANVISA. Agência Nacional de Vigilância Sanitária. Resolução RDC no 216, de 15 de setembro de 2004. Dispõe sobre o Regulamento Técnico de Boas Práticas para Serviços de Alimentação. D.O.U. de 16/09/2004.

ARAÚJO, J. M.; GÜNTHER, W. M. R. Riscos à Saúde em Áreas Contaminadas: contribuições da teoria social. Saúde e Sociedade, v. 18, n. 2, p. 312-324, 2009.

AZEVEDO, E. Reflexões sobre riscos e o papel da ciência na construção do conceito de alimentação saudável. Revista de Nutrição, v. 21, n. 6, p. 717-723, 2008.

BASTI, A. A.; MISAGHI, A.; SALEHI, T. Z.; KAMKAR,A. Bacterial pathogens in fresh, smoked and salted Iranian fish. Food Control, v. 17, p. 183-188, 2006.

BATISTA, V. S.; PETRERE Jr., M. Spatial and temporal distribution of fishing resources exploited by the Manaus fishing fleet, Amazonas, Brazil. Brazilian Journal of Biology, v. 67, n. 4, p. 651-656, 2007.

BARROS, G. C. Perda de qualidade do pescado, deteriora e putrefação. Revista do Conselho Federal de Medicina Veterinária, n. 30, p. 59-64, 2003.

BRASIL. Secretaria Especial de Aquicultura e Pesca. Boletim estatístico da pesca e aquicultura: Brasil 2010. Brasília: SEAP, 2012, 129 p.

CARTIER, R.; BARCELLOS, C.; HUBNER, C.; PORTO, M. F. Vulnerabilidade social e risco ambiental: uma abordagem metodológica para avaliação de injustiça ambiental. Caderno de Saúde Pública, v. 25, n. 12, p. 2695-2704, 2009.

ENGEL-COX, J.; VAN HOUTEN, B.; PHELPS, J.; ROSE, S. Conceptual model of comprehensive research metrics for improved human health and environment. Ciência \& Saúde Coletiva, v. 14, n. 2, p. 519-531, 2009.

FIGUEIREDO, J. A. S.; DRUMM, E.; RODRIGUES, M. A. S.; SPILKI, F. R. The Rio dos Sinos watershed: an economic and social space and its interface with environmental status. Brazilian Journal of Biology, v. 70, n. 4, p. 1131-1136, 2010.

GAMA, A. F.; OLIVEIRA, A. H. B.; CAVALCANTE, R. M. Inventário de agrotóxicos e risco de contaminação química dos recursos hídricos no semiárido cearense. Química Nova. 2013, v. 36, n. 3, p. 462-467.

GERMANO, P. M. L.; GERMANO, M. I. S. Higiene e Vigilância Sanitária de Alimentos. São Paulo: Manole, 2008. 986p.

GOMES, F. S. Frutas, legumes e verduras: recomendações técnicas versus constructos sociais. Revista de Nutrição, v. 20, n. 6, p. 669-680, 2007.

GONÇALVES, C. D. Desastres naturais - algumas considerações: vulnerabilidades, risco e resiliência. Territorium, n. 19, p. 5-14, 2012. 
HABERMANN, M.; GOUVEIA, N. Environmental Justice: an ecossocial health approach. Revista de Saúde Pública, v. 42, n. 6, p. 1105-1111, 2008.

HAMADA-SATO, N.; USUI,K.; KOBAYASHI, T.; IMADA, C. W. E. Quality assurance of raw fish base on HACCP concept. Food Control, v. 16, p. 301-307, 2005.

HELMAN, H.; ANDERY, P. R. P. Análise de falhas: aplicação dos métodos de FMEA e FTA. Belo Horizonte: Fundação Christiano Ottoni, 1995. 174 p.

ILIZALITURRI, C. A.; GONZÁLE Z-MILLE, D.; PELALLO, N. A.; DOMÍNGUEZ, G.; MEJÍA-SAAVEDRA, J.; DOSAL, A. T.; PÉREZ-MALDONADO, I.; BATRES, L. DÍAZBARRIGA, F.; ESPINOSA-REYES, G. Revisión de las metodologías sobre evaluación de riesgos en salud para el estudio de comunidades vulnerables en América Latina. INCI, v. 34, n. 10, p. 710-717, 2009.

LAURENTI, R.; VILLARI, B. D.; ROZENFELD, H. Problemas e melhorias do método FMEA: uma revisão sistemática da literatura. P\&D em Engenharia de Produção, v. 10, n. 1, p. 59-70, 2012.

LEAL, F.; PINHO, A. F.; ALMEIDA, D. A. Análise de falhas através da aplicação do FMEA e da Teoria Grey. Revista Gestão Industrial, v. 02, n. 1, p. 78-88, 2006.

LIN, W.; WANG, B.; LI, J.; WANG, X.; ZENG, L.; YANG, L.; LIN, H. The impact of urbanization on the monthly averaged diurnal cycle in October 2004 in the Pearl River Delta region. Atmósfera, v. 23, n. 1, p. 37-51, 2010.

LUCCA, A.; TORRES, E. A. Condições de higiene de "cachorro-quente" comercializado em vias públicas. Revista de Saúde Pública, São Paulo, v. 36, n. 3, p. 350-352, 2002.

LUNDGREN, P. U; SILVA, J. A; MACIEL, J. F; FERNANDES, T. M. Perfil da Qualidade Higiênico-Sanitária da Carne Bovina Comercializada em Feiras Livres e Mercados Públicos de João Pessoa/PB-Brasil. Alimentos \& Nutrição, v. 20, n. 1, p. 113-119, 2009.

MENDES, R. A.; AZEREDO, R. M. C.; COELHO, A. I. M. Contaminação por Bacillus cereus em superfícies de equipamentos e utensílios em unidade de alimentação e nutrição. Ciência \& Saúde Coletiva, v. 16, n. 9, p. 3933-3938, 2011.

NASCIMENTO, G. A.; BARBOSA, J. S.; CHIRADIA, A. C. N. Levantamento das condições sanitárias dos quiosques das praias de Camburi e Curva da Jurema, da cidade de Vitória, Espírito Santo. Revista Higiene Alimentar, São Paulo, v. 21, n. 152, p. 18-24, 2007.

OVRETVEIT, J. Contemporary quality improvement. Caderno de Saúde Pública, v. 29, n. 3, p. 424-426, 2013. 
OZILGEN, S. Failure Mode and Effect Analysis (FMEA) for confectionery manufacturing in developing countries: Turkish delight production as a case study. Ciência e Tecnologia de Alimentos, v. 32, n. 3, p. 505-514, 2012.

RAMOS, E. F. A gestão de Riscos usando FMEA. Revista Mundo PM, n. 10, p. 71 74, 2006.

REIJ, M. W.; DEN, A. E. D. Recontamination as source of pathogens in processed foods. International Journal of Food Microbiology, v. 91, p. 1-11, 2004.

ROCHA, H. C; COSTA, C.; CASTOLDI, F. L.; CECCHETTI, D.; CALVETE, E. O.; LODI, B. S. Perfil socioeconômico dos feirantes e consumidores da Feira do Produtor de Passo Fundo, RS. Ciência Rural, v. 40, n. 12, p. 2593-2597, 2010.

ROSSATO, M. V.; LIMA, J. E.; LIRIO, V. S. Condições econômicas e nível de qualidade ambiental no estado do Rio Grande do Sul. Revista de Economia e Sociologia Rural, v. 48, n. 3, p. 587-604, 2010.

SAITO, S. M.; PELLERIN, J. R. G. M. Avaliação da gestão de risco de escorregamentos no macico do morro da Cruz, Florianópolis, SC. R. Ra'e Ga, v. 29, p. 47-63, 2013.

SÁNCHEZ-ORTIZ, I. A.; LEITE, M. A. Fatores de risco da transmissão de zoonoses por costumes da população de Ilha Solteira, Brasil. Revista de Salud Pública, v. 13, n. 3, p. 504-513, 2011.

SANT'ANNA, A. P.; PINTO, R. P. S. Composição probabilística no cálculo das prioridades na FMEA. Revista Eletrônica Sistemas \& Gestão, v. 5, n. 3, p. 179$191,2010$.

SCHLUNDT, J. New directions in foodborne disease prevention. International Journal of Food Microbiology, v. 78, p. 3-17, 2002.

SCOTT, B. S.; WILCOCK, A. E.; KANETKAR, V. A survey of structured continuous improvement programs in the Canadian food sector. Food Control, v. 20, n. 3, p. 209-217, 2009.

SILVA, C. A. M. C.; CAMPOS, J. C.; FERREIRA, J. A.; MIGUEL, M. A. L.; QUINTAES, B. R. Caracterização microbiológica de lixiviados gerados por resíduos sólidos domiciliares e de serviços de saúde da cidade do Rio de Janeiro. Eng. Sanitária e Ambiental, v.16, n. 2, p. 127-132, 2011.

SILVA, E.; CEREJEIRA, M. J. Avaliação do risco de pesticidas individuais e suas misturas em águas de superfície. Revista de Ciências Agrárias, v. 35, n. 2, p. 3242, 2012. 
SILVA, G. S.; MIOLA, S.; SILVA, G. S.; SOUSA, E. R. Avaliação da qualidade das águas do Rio São Francisco Falso, tributário do reservatório de Itaipu, Paraná. Revista Eclética Química, v. 35, n. 3, p. 117-122, 2010.

SOUZA, L. H. L. A manipulação inadequada dos alimentos: Fator de contaminação. Revista Higiene Alimentar, v. 20, n. 146, p. 32-39, 2006.

TSAROUHAS, P. H.; ARVANITOYANNIS, I. S.; AMPATZIS, Z. D. A case study of investigating reliability and maintainability in a Greek juice bottling medium size enterprise (MSE). Journal of Food Engineering, v. 95, n. 3, p. 479-488, 2009.

ZAMBRANO. T. F.; MARTINS, M. F. Utilização do método FMEA para avaliação do risco ambiental. Gestão \& Produção, v. 14, n. 2, p. 295-309, 2007.

ZANIN, E. M.; SANTOS, J. E.; HENKE-OLIVEIRA, C. Environmental analysis and zoning for an urban park management purpose. Brazilian Archives of Biology and Technology, v. 48, n. 4, p. 647-655, 2005. 